\title{
The Polonium-210 Public Health Assessment: The Need for Medical Toxicology Expertise in Radiation Terrorism Events
}

\author{
Jeffrey B. Nemhauser
}

Published online: 25 May 2010

(C) American College of Medical Toxicology 2010

In 1989, the Centers for Disease Control and Prevention (CDC) brought together a group of subject matter experts to form the Radiation Studies Branch (RSB). CDC tasked the RSB staff with assessing potential environmental health impacts of radiation released from US Department of Energy nuclear weapons production facilities. Shortly after the September 11, 2001 attacks, however, the mission of the RSB expanded to include (and to focus on) preparing the nation's public health community, healthcare providers and citizens for intentional (i.e., terrorism-related) radiological incidents, accidents involving exposures to radiation, and unintentional environmental releases of radioactive materials.

In late 2006, an event occurred in the UK for which the RSB was uniquely suited to respond. The radioactive isotope polonium-210 $\left({ }^{210} \mathrm{Po}\right)$ was deliberately used as a weapon against one person and, perhaps accidentally, released into the environment. Initially, it was unclear how many bystanders might have been unintended victims of the radioactive chemical. Some of those bystanders included American citizens travelling abroad at the time.

The health physics and medical staff of the RSB promptly responded to requests for assistance from the US

The findings and conclusions in this report are those of the authors and do not necessarily represent the official position of the Centers for Disease Control and Prevention or the Agency for Toxic Substances and Disease Registry.

J. B. Nemhauser $(\square)$

Radiation Studies Branch,

National Center for Environmental Health,

Centers for Disease Control and Prevention,

4770 Buford Highway NE, Mail Stop F-58,

Atlanta, GA 30341, USA

e-mail: jnemhauser@cdc.gov
Department of State and the Health Protection Agency (HPA) of the UK to screen American citizens who had possibly come into contact with ${ }^{210} \mathrm{Po}$ during their travel abroad. RSB staff also provided guidance and advice to individual citizens and to their physicians, to the US Department of Health and Human Services, to the media, and to the public at large about potential risks of adverse health effects from internal contamination. Finally, RSB staff helped coordinate the collection of biological specimens from concerned US citizens and provided interpretation of those results.

In the autumn of 2006, residents of and visitors to London were held hostage by something they could not see, hear, smell, or taste: the radioactive isotope, ${ }^{210} \mathrm{Po}$. The apparent target of this deadly substance was a single individual-a former KGB agent who was an outspoken critic of the Russian government, Alexander Litvinenko. Indeed, approximately 3 weeks after the isotope had been smuggled into England and poured into his tea, Mr. Litvinenko succumbed to ${ }^{210} \mathrm{Po}$ poisoning. But although this Russian dissident was the specific target, by the end of November, British officials had identified others who had been contaminated - presumably inadvertently-with this radioactive material. In the interim, other officials were discovering a forensic trail of ${ }^{210} \mathrm{Po}$ throughout London and its suburbs.

The spread of radiological material into the environment (whether by means of explosion or by simple dispersion) is what defines a radiological dispersal device (RDD) event. ${ }^{1}$ Inadvertent releases of radiological material may reasonably be classified as RDD "type" events as well. In Goiânia, Brazil (1987), for example, metal scavengers

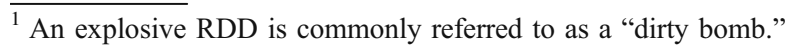


found an unused piece of radiation therapy equipment in an abandoned cancer treatment center. ${ }^{2}$ When later cut open at a junkyard, the orphaned piece of equipment released a small but highly radioactive quantity of cesium-137 $\left({ }^{137} \mathrm{Cs}\right)$. Ultimately, few people died as a result, but the environmental and psychological impact of what amounted to something less than two tablespoons of ${ }^{137} \mathrm{Cs}$ were significant. Cleanup of the contaminated area involved the evacuation and destruction of more than 40 homes. Thirty-five hundred cubic meters (the equivalent of 275 truckloads) of waste was removed and stored at a distance. More than 110,000 people from areas in and around Goiânia sought monitoring and reassurance while at the same time being ostracized by the rest of their country.

Around the world today, there is increasing concern about the possibility of the deliberate release of radiological materials as a means of inciting economic and political disruption. One might argue that the perpetrators of the London event neither desired nor planned the indiscriminate spread of ${ }^{210} \mathrm{Po}$ around that city. Nonetheless, the response provided the public health community (particularly in the UK, but also internationally) with a scenario approximating a large-scale RDD event. Although relatively few people were actually contaminated with radiological material, as in Goiânia, the ${ }^{210} \mathrm{Po}$ incident incited widespread psychological concern and a heightened political and public health response.

As public health agencies within the USA prepare to respond to a possible domestic RDD event, the need for collaboration between medical toxicologists, health physicists, and practitioners of public health is critical. Clinicians and the public health community will be confronted - as were our British colleagues - with the dilemma of how to manage toxicity from radiological materials on a large scale. Questions about whom to screen, how to screen, and whom to treat and how will dominate the public health response to an RDD event. For some isotopes that could be used in an RDD, answers to these questions will not be immediately apparent and the assistance provided to the public health community by medical toxicologists will be invaluable. Using the 2006 London ${ }^{210} \mathrm{Po}$ incident as a case in point, this article will address the various points at which medical toxicologists and public health officials will need to work jointly in responding to and managing a population affected by an RDD.

\footnotetext{
${ }^{2}$ For complete details of the incident, see The Radiological Accident in Goiânia. International Atomic Energy Agency (IAEA), Vienna. 1988 (http://www-pub.iaea.org/MTCD/publications/PDF/Pub815 web.pdf).
}

\section{Isotope Identification}

Authorities responding to the detonation of an incendiary device will likely be alerted to the possibility of radiological contamination by using radiation survey meters capable of detecting gamma radiation. These devices have become standard equipment for many first responders-certainly those in larger metropolitan areas routinely carry them.

In London, by contrast, no explosion heralded the release of ${ }^{210} \mathrm{Po}$ into the environment. Even had an explosive device been used, few first responders would have had ready access to the specialized equipment necessary to detect polonium, which undergoes almost pure alpha particle decay. It was not until after healthcare providers successfully identified the offending toxicant (shortly after the death of Mr. Litvinenko) that public health officials and radiation control personnel began to conduct an environmental search for ${ }^{210}$ Po by using probes specifically designed to detect alpha radiation. For several reasons, then, including its clandestine release and particularly its physical properties, polonium went undetected for the better part of a month.

In either case (whether announced by an explosion or covertly released), once radiological materials have been detected, confirmation of their presence should be made by public health officials working in tandem with health physicists and others with radiation control expertise. Subsequent decisions-whom to screen, how to screen, whom to treat and with what antidotes or therapies-will derive from accurate identification of the isotope or isotopes. The physical properties of the isotopes involved, specifically their mode of decay, provide the signature by which they may be identified. And once the isotopes are identified, distinguishing internally contaminated members of the public (persons in greatest need of medical countermeasures) from those who are not will be among the most important early public health priorities after an RDD event. $^{3}$

The majority of radioactive isotopes that could be used in an RDD event are toxic metals. Medical toxicologists and Certified Specialists in Poison Information are uniquely qualified to provide guidance about the treatment of persons poisoned with metals. Once an isotope is identified, therefore, initiating close consultation with Poison Control Centers and the clinical toxicology community becomes crucial. Even when a toxicant is unfamiliar or rare, toxicology subject matter experts have both the knowledge

\footnotetext{
${ }^{3}$ This in addition to delivering medical care, providing for a safe, orderly, and expeditious evacuation, issuing shelter-in-place instructions where appropriate, ensuring that power, water, and communications infrastructures are restored, and overseeing culturally sensitive handling and disposition of the deceased.
} 
base and the familiarity with various health resources to enable them to make educated treatment recommendations and management decisions.

For example, public health officials, healthcare providers, and the public began seeking information about polonium as soon as it had been identified in $\mathrm{Mr}$. Litvinenko's bodily fluids and then at sites in and around London. Several articles written prior to 2006 discussed the biological fate of polonium in the environment and the resultant health effects (primarily in laboratory animals) when it is internalized [1-5]. In addition, various authors had attempted to identify chelating agents of high efficacy, some with variable degrees of success [6-11]. Lengthy and comprehensive reviews devoted to polonium - including a report on its biokinetics - and articles specifically about ${ }^{210}$ Po were generally directed toward specialists in health physics [12-15]. Few of these articles appeared in the medical literature and public health officials had a limited understanding about the toxicity of polonium. As a group, medical toxicologists are well suited to identify, understand, and interpret arcane scientific literature for their colleagues and the public. In any future events involving the release of radiological material, then, healthcare providers and the public health community would be well advised to consult with these specialists.

\section{Screening for Internal Contamination}

When radioactive materials are spread by non-explosive dispersal - intentionally or not - the delay between their release and the point at which people seek medical attention can be prolonged. In Goiânia, for example, it was weeks before affected villagers sought assistance. A total of four people died and a sizable group of others were contaminated sufficiently to require treatment with medical countermeasures. It was not until after public health and radiation control authorities had begun to delimit the spread of contamination and sort out who was contaminated (and who was not) that healthcare providers had a better sense of who among the concerned citizenry would actually require medical treatment. Similarly, in London in 2006, public health officials developed protocols for screening well after the initial release of radiological material into the environment.

Screening for internal contamination from radioactive isotopes is a nuanced process. Decisions about whom to screen (and in what order) should be made by public health officials and based on epidemiological data. In the UK, the HPA developed fairly strict criteria by which residents of London could be stratified according to their likelihood of internal contamination. A person's likelihood of contamination was based on his or her proximity to Mr. Litvinenko while he was ill or at some time during the day on which he was poisoned. Those deemed more likely to have been contaminated were eligible to receive laboratory screening for ${ }^{210}$ Po. Adherence to the criteria was particularly crucial because of two related limitations: (1) the physical properties of the isotope in question made reliance on sophisticated laboratory methods necessary and rapid mass screening unrealistic and (2) the existing laboratory infrastructure by which screening could take place was insufficient to accommodate large numbers of people who-in the absence of a high index of suspicion-were primarily seeking reassurance.

Detecting external radiological contamination at or above the level of the clavicles should raise the index of suspicion for internal contamination via the oral or the respiratory route. This is true for any isotope regardless of its decay scheme. Identifying internal contamination by means of external monitoring is, however, limited to those isotopes that have either a prominent or a characteristic gamma or high-energy beta decay signature. External monitoring for these isotopes can potentially expedite the process of screening for internal contamination, thereby enabling public health officials to triage many more people in a shorter period of time than could be achieved by other methods. In order to make this type of screening expeditious and effective, sufficient numbers of adequately trained personnel using properly calibrated equipment must be available.

By contrast, internalized alpha particles do not have sufficient energy to penetrate the body, and they cannot be detected by external monitoring. Establishing that alphaemitting isotopes (like ${ }^{210} \mathrm{Po}$ ) have been inhaled, ingested, or otherwise taken into the body requires laboratory testing of biological samples. For uncommonly encountered isotopes such as polonium, trying to ascertain whether internal contamination has occurred may not happen quickly. Most commercial laboratories do not have the requisite capacity to analyze biological samples for radiological contamination of any type. Laboratories capable of performing bioassays generally do so for the purposes of occupational surveillance and not for rapid screening; turnaround times for results may be prolonged. Thus, the inherent physical properties of ${ }^{210} \mathrm{Po}$ constrained its rapid identification (and quantification) in internally contaminated individuals. This became one of the first obstacles encountered by the HPA as they considered how best to screen the populace.

The scarcity of clinical laboratories able to assay for polonium hampered the HPA's ability to provide screening for all who desired it. This, then, was the impetus for public health officials in the UK to create a prioritization system for sample collection. Establishing a scheme whereby risk for internal contamination could be established therefore became a prominent public health concern in the days and 
weeks after the discovery of ${ }^{210} \mathrm{Po}$ in the environment. In truth, even when rapid screening can be readily implemented after a radiation event, it will still be necessary to develop criteria that enable officials to prioritize sampling-especially when there are large numbers of people seeking reassurance. In Goiânia, for example, it took officials using hand-held radiation survey meters many months to screen the over 110,000 concerned citizens who sought screening for possible internal contamination from ${ }^{137} \mathrm{Cs}$.

As soon as screening results for internal contamination become available, public health (and other) officials will be expected to provide guidance about resource allocation, especially where medical countermeasures specific to the implicated toxicant may be in limited supply. Together with experts in radiation medicine and medical toxicology, public health personnel will need to ascertain who among the internally contaminated are most likely to benefit from available countermeasures.

\section{Treating Internal Contamination}

Prior to the assassination of Alexander Litvinenko, few experts anticipated use of ${ }^{210} \mathrm{Po}$ as a murder weapon. The events of November 2006, however, stimulated and reinvigorated worldwide interest in this relatively obscure element, and those events prompted the authoring of many new articles in the literature about its toxicity and the public health response to this event [16-24]. Articles concerning the "biological behavior" of this element have expanded our knowledge about its potential use as a poison. Since the element is highly toxic, internal contamination with even minute doses of it can prove deadly, as was the case for Mr. Litvinenko. Used industrially as an antistatic agent, polonium had at one time been packaged and marketed commercially to remove dust and static electricity from the surfaces of vinyl long-playing record albums. Ubiquitous in the environment, it is a "daughter" in the radon decay chain and is concentrated within the leaves of various plants, including tobacco.

Ultimately, decisions about managing victims of intentional poisoning on a large scale will be the responsibility of public health at the local, state, tribal, and federal levels. Each patient will, however, require the individualized attention and judgment of a healthcare professional experienced in delivering care to critically intoxicated people. Because of their particular and unique experience in administering medical countermeasures (including chelating agents) to intoxicated patients, medical toxicologists will assume an important role in managing the victims of radiological and nuclear events.

Moreover, when specific medical countermeasures do not exist or have not been approved for use, clinical toxicologists will be asked to provide guidance about reasonable alternatives. Even if the physicians caring for Mr. Litvinenko had suspected (and had been able to rapidly confirm) polonium poisoning, there is no accepted treatment regimen for this isotope. This same observation applies to many of the radiological materials that could be made into intentional (or unintentional) radiological dispersal devices. A recently published review summarizes possible, but by no means universally accepted chelation options for polonium poisoning [25]. None of the options provided has been tested in humans; several had significant limitations identified by experimental animal studies. Sorting out clinical treatment decisions, then (particularly where none exist), necessitates integrating toxicologists into the teams responsible for delivering care.

Medical toxicologists may also be trusted advisers when decisions about scarce resource allocation need to be made. In London, only one person was significantly poisoned. In Goiânia, 46 people required treatment with insoluble Prussian blue [ferric(III) hexacyanoferrate]. Should a large-scale, multiple-venue RDD event occur in the USA today, however, the public health and medical communities might find medical countermeasures specific for the isotope in question to be in short supply. In such cases, delivery of countermeasures should be directed toward those in greatest need. The ethical allocation of scarce resources will be guided in part by the clinical status of each patient, and the ability to clinically assess intoxicated patients is the appropriate responsibility of medical toxicologists.

In addition to recommending and administering radiation medical countermeasures, toxicologists will play a role in assessing and monitoring the clinical response to medical interventions. Medical toxicologists will be tasked with tracking the excretion of isotopes and-with the support of hospital radiation safety personnel-making recommendations to the other healthcare providers and staff about proper sample collection and handling. Ultimately, toxicologists should be part of any hospital team making decisions about whether radioactively contaminated patients are responding to treatment and how well.

\section{Conclusion}

The London ${ }^{210} \mathrm{Po}$ incident affected very few people medically, but many more so psychologically. Through careful handling of the situation - and then over a period of many months - HPA staff worked to allay the British public's fears by characterizing the event as a targeted murder and then rapidly identifying and screening selected members of the public [26]. In the USA, the RSB undertook an effort to identify and screen US citizens returning from London who could potentially have been 
contaminated with ${ }^{210} \mathrm{Po}$. Like their counterparts in the UK, RSB staff provided guidance and information about health risks to potentially affected citizens.

Had the environmental contamination been more indiscriminate or had the victim of the poisoning been less accurately targeted, the efforts of both the HPA and the CDC would have required the assistance of a much larger cadre of professionals. In fact, it is likely that most RDD "type" events, intentional or otherwise, will involve many more individuals than were affected in London. The more than 110,000 individuals who requested screening after the Goiânia event would suggest such to be the case; fortunately, none of them was found to be contaminated. But in a true terrorist event, a sizable proportion of the public could become internally contaminated with radioactive material, and some heavily so. At that point, the medical and public health communities would do well to look to clinical toxicologists to provide necessary guidance about identifying, screening for the presence of, and treating victims of radiological terrorism.

\section{References}

1. Stannard JN (1964) Distribution and excretion of polonium-210. I. Comparison of oral and intravenous routes in the rat. Radiat Res Suppl 5:49-59

2. Morrow PE, Smith FA, Dellarosa RJ, Casarett LJ, Stannard JN (1964) Distribution and excretion of polonium-210. II. The early fate in cats. Radiat Res Suppl 5:60-66

3. Stannard JN (1964) Distribution and excretion of polonium-210. III. Long-term retention and distribution in the rat. Radiat Res Suppl 5:67-79

4. Stannard JN, Baxter RC (1964) Distribution and excretion of polonium-210. IV. On a multiple-dose regimen. Radiat Res Suppl 5:80-92

5. Stannard JN, Casarett GW (1964) Concluding comments on biological effects of alpha-particle emitters in soft tissue as exemplified by experiments with polonium 210. Radiat Res Suppl $5: 398-434$

6. Hursh JB (1951) The effect of BAL on the excretion and tissue distribution of polonium in rats. J Pharmacol Exp Ther 103 (4):450-459

7. Hursh JB (1952) Effect of BAL on survival of rats after lethal doses of polonium. Proc Soc Exp Biol Med 79(2):210-212

8. Aposhian HV, Dart RC, Aposhian MM, Dawson BV (1987) Tissue decorporation in rats by DMPA. Res Commun Chem Pathol Pharmacol 58(2):157-171
9. Bogdan GM, Aposhian HV (1990) N-(2,3-dimercaptopropyl) phthalamidic acid (DMPA) increases polonium-210 excretion. Biol Metals 3:232-236

10. Rencová J, Svoboda V, Holuša R, Volf V, Jones MM, Singh PK (1997) Reduction of subacute lethal radiotoxicity of polonium-210 in rats by chelating agents. Int J Radiat Biol 72(3):341-348

11. Rencová J, Volf V, Jones MM, Singh PK (2000) Mobilization and detoxification of polonium-210 in rats by 2,3-dimercaptosuccinic acid and its derivatives. Int J Radiat Biol 76(10):1409-1415

12. Health Risks of Radon and Other Internally Deposited AlphaEmitters: BEIR IV (1988). Chapter 3: Polonium. http://www.nap. edu/openbook/0309037972/html/159.html, Accessed February 23, 2010

13. Stannard JN (1988) Chapter 4: polonium and thorium. In: Radioactivity and health: a history. Office of Scientific and Technical Information, Springfield, VA

14. International Agency for Research on Cancer (2001) Ionizing radiation, part 2: Some internally deposited radionuclides, vol 78 . IARC Monographs on the Evaluation of Carcinogenic Risks to Humans. International Agency for Research on Cancer, Lyon, France

15. Leggett RW, Eckerman KF (2001) A systemic biokinetic model for polonium. Sci Total Environ 275:109-125

16. Chin FKC (2007) Scenario of a dirty bomb in an urban environment and acute management of radiation poisoning and injuries. Singapore Med J 48(10):950-957

17. Harrison J, Leggett R, Lloyd D, Phipps A, Scott B (2007) Polonium-210 as a poison. J Radiol Prot 27:17-40

18. Le M (2007) Polonium 210, exposed. J Med Toxicol 3(2):82-84

19. Scott BR (2007) Health risk evaluations for ingestion exposure of humans to polonium-210. Dose Response 5(2):94-122

20. Stather JW (2007) The polonium-210 poisoning in London. J Radiol Prot 27(1):1-3

21. Anderson JL, Spitz HB, Daniels RD (2008) Population monitoring for acute exposure to ${ }^{210}$ Po. J Occup Environ Med 50(8):916-923

22. Brosh-Nissimov T, Havkin O, Davidovitch N, Poles L, Shapira C (2008) Suspected radioactive contamination: evaluation of 45 Israeli citizens potentially exposed to polonium-210 in London. Isr Med Assoc J 10(2):99-103

23. Cornett J, Tracy B, Kramer G, Whyte J, Moodie G, Auclair JP, Thomson D (2009) Polonium-210: lessons learned from the contamination of individual Canadians. Radiat Prot Dosimetry 134(3-4):164-166

24. McFee RB, Leikin J (2009) Death by polonium-210: lessons learned from the murder of former Soviet spy Alexander Litvinenko. Semin Diagn Pathol 26(1):61-67

25. Jefferson RD, Goans RE, Blain PG, Thomas SHL (2009) Diagnosis and treatment of polonium poisoning. Clin Tox 47:379-392

26. Rubin GJ, Page L, Morgan O, Pinder RJ, Riley P, Hatch S, Maguire H, Catchpole M, Simpson J, Wessely S (2007) Public information needs after the poisoning of Alexander Litvinenko with polonium-210 in London: cross sectional telephone survey and qualitative analysis. BMJ 335(7630):1143 